\title{
Senior High School Students' Perceptions of Internationalization of Higher Education
}

\author{
Tsung-Ming Liu \\ National Chi Nan University, Nantao, Taiwan
}

\begin{abstract}
Due to the dramatic increase of higher education institutions during the past decades, senior high school students in Taiwan have enjoyed easier access to higher education than never before. On the other hand, colleges and universities are facing unprecedented competition on recruitment of students with the tendency of fewer children worsening year after year. To cope with this challenge, internationalization has become an important strategy to attract students both from abroad and domestically. Because domestic students still constitute the main part of the student body in each college and university so far, it is important to understand how senior high school students perceive internationalization of higher education. The purpose of this study is to investigate senior high school students' perceptions of internationalization in colleges and universities in Taiwan, which can be put into consideration by staff of higher education sectors looking for strategies to boost the sustainability and competitiveness in higher education institutions. Eight senior high school students were interviewed to explore their perceptions of internationalization in colleges and universities. Findings suggest that internationalization is a significant factor that affects students' choice of colleges and universities and is supported by most students. The main theme of students' perceptions of internationalization is "walking out" to know more about different cultures in other countries. Concerns emerge when foreign language competency is insufficient or opposition from parents interferes with students' plans to go abroad. Domestic students might also be afraid that recruiting international students may influence their admission opportunities. Necessity of some practices needs to be considered. Recommendations are proposed for students, higher education sectors, and future researchers.
\end{abstract}

Keywords: senior high school students, perception, internationalization of higher education

\section{Introduction}

With the booming of higher education institutions in Taiwan during the past decades, senior high school students enjoy much more opportunities to access higher education than ever before. In 1950, there were only eight colleges and universities in Taiwan and only elites of the society could have higher education. The number went up dramatically and reached its peak of 163 in 2006, and then there was a slight decline. By the year 2014, there were still 159 colleges and universities in Taiwan (Ministry of Education, 2015), far more than neighboring areas and countries in terms of the population size of this island. Higher education has become a popular choice of ordinary people after they graduate from high school.

On the other hand, the competition on recruiting students among colleges has toughened unprecedentedly with the trend of fewer children worsening year after year. To cope with this competition, internationalization

Tsung-Ming Liu, Ph.D. candidate, Department of International and Comparative Education, National Chi Nan University. 
has become an important strategy for many colleges and universities. The purpose of internationalization has two folds in this issue - to recruit international students and to attract domestic high school graduates. In recent years, more and more elite senior high school graduates decide to go to colleges in Hong Kong and mainland China. In addition to excellent scholarship, internationalization is the key reason for the decision made by those students (Feng, 2015). So far, domestic students still constitute the major part of the student body in colleges and universities, but the trend of going international is noteworthy. It is important, therefore, to understand how senior high school students perceive internationalization of higher education, because higher level of internationalization may be more attractive to students and improve recruitment of new students.

The purpose of the present study is to investigate senior high school students' perceptions of internationalization in universities in Taiwan. The verb "perceive" means "to become aware, know, or identify by means of senses". It also means "to recognize, discern, envision, or understand" (Dictionary.com, 2015). The noun form of the word "perceive" is "perception" and can be understood as knowledge, understanding, and attitudes towards something. In the present study, it refers to knowledge, understanding, and attitudes towards internationalization of higher education. Recommendations will be proposed for students, higher education sectors, and future researchers according to the results. The research questions are as follows:

1. What do senior high school students think of the internationalization practices in colleges and universities?

2. How do internationalization practices in colleges and universities affect senior high school students' choice of colleges or universities?

\section{Literature Review}

\section{Definition of Internationalization of Higher Education}

Internationalization has become a common term widely used in contexts that involve more than one nation. However, it is still difficult to give it an exact definition due to the complexity of its nature. So far, there is not a commonly agreed definition of the term by researchers. Different researchers describe internationalization of higher education differently according to their own perspectives. Some focus on foreign language education while others emphasize the exchange of teachers and students with other countries. Still some others argue that educational exchange and technological cooperation are the key points (Yang, 2004).

Some researchers hold that internationalization is a process. Knight (1993) saw internationalization of higher education as the process of integrating an international/intercultural element into the teaching, research, and service functions of the institution. This definition describes internationalization as a dynamic process than a set of fixed activities and points to the basic functions of a higher education institution - teaching, research, and service. A similar definition was proposed by Maudarbekova and Kashkinbayeva (2014), who defined internationalization of education as the process including international aspects in the research, teaching, and administrative activities of schools. Ellingboe (1998) explained that internationalization is a complex process of incorporating an international perspective into a higher education institution "that involves many stakeholders working to change the internal dynamics of an institution to respond and adapt appropriately to an increasingly diverse, globally focused, ever-changing external environment" (p. 199). However, detailed projects and plans are needed when it comes to practice in real situations.

Hamrick (1999) argued that there are at least four ways to describe internationalization in higher education. The traditional view of internationalization includes the academic activities under the heading of "International 
Studies", including various courses that develop intercultural adaptability. A second view of internationalization includes activities that facilitate the interaction of domestic students with foreign students and faculty to build a sense of global community, such as studying abroad and recruitment of international students and faculty. The third view is international education as foreign aid or technical assistance to other countries, primarily developing countries. The fourth view on internationalization is preparing people to function in an increasingly international and culturally diverse environment. Evidently, these four views are not mutually exclusive and are all parts of the concept of internationalization.

Yang (2004) argued that internationalization is usually defined by the activity perspective. At the same time, definition of internationalization is country-specific. To adjust to the nature of senior high school students who have not had much experience in this field, the present study defines internationalization of higher education as activities held by colleges or universities to increase the interaction between domestic students and foreign students and faculty. Those activities include academic exchange with foreign colleges or universities, professional courses taught in English, English proficiency training for all students, recruiting international students, recruiting international faculty, faculty exchanges with foreign colleges or universities, students exchanges with foreign colleges or universities, and setting up mutually recognized courses and programs with foreign colleges or universities.

\section{Reasons for Internationalization of Higher Education}

The importance of internationalization of higher education seems to be widely recognized both by the administrative and academic sectors. More and more countries are formulating various policies to internationalize their higher education institutions. Japan has a comprehensive account of strategies to increase the level of internationalization of its universities in the 2008 White Paper on Education, Culture, Sports, Science and Technology (Ministry of Education, Culture, Sports, Science and Technology, Japan, 2008). The European University Association (EUA), with approximately 850 members in 47 countries, stated in its 2013 membership consultation survey that $99 \%$ of institutions that replied to the survey either have an internationalization strategy in place (56\%), intend to develop one (13\%), or have considered internationalization in other strategies (30\%). In Taiwan, Ministry of Education (2001) proposed the White Paper on University Education Policy in which the insufficiency of internationalization in higher education is identified and related policies are rendered to address the issue.

Several reasons for internationalization of higher education have been offered by researchers in different levels-personal, institutional, national, and global. At the personal level, internationalization offers opportunities for students and faculty to gain new perspectives and be internationally oriented (Bordean \& Borza, 2013). At the institutional level, there are several reasons for internationalization. First, internationalization provides financial benefits from recruiting international students which help a college or university survive in the highly competitive environment (Qiang, 2003). Second, internationalization of higher education is a key criterion in the majority of university rankings. Higher level of internationalization gives advantage to a college or university in coping with the pressure of becoming more entrepreneurial (Anderseck, 2004; Deem, Mok, \& Lucas, 2008). Third, internationalization yields new perspectives in terms of quality assurance within universities (Bordean \& Borza, 2013). At the national level, Ardakani, Yarmohammadian, Abari, and Fathi (2011) claimed that internationalization is an efficient strategy to fulfill the various needs of the international community. This is considered from the national economic perspective. The economic benefits 
of internationalization include national income from the expenses of international students in the country and the development of internationally competitive workforce to meet the demands of globalized society, economy, and labor markets (Qiang, 2003). At the global level, the reason for internationalization lies in the nature of higher education itself. One of the missions of colleges and universities is the pursuit of universal knowledge that transcends national borders. Using the knowledge to raise human well-being is usually not restricted in a nation. Therefore, one of the reasons for internationalization of higher education is based on the nature of higher education to pursue universal knowledge and human well-being for all (Yang, 2004).

\section{Internationalization as Attraction to Senior High School Students}

Internationalization of higher education has been practiced in many colleges and universities around the world. In Taiwan, many colleges and universities also have units of school administration that deal with affairs of internationalization. In the mission or philosophy statement, many universities include internationalization as a key element to enhance their attractiveness. For example, the first item of mission statement of National Chi Nan University (NCNU), a public university in central Taiwan, is to develop students' forward-thinking and international perspective (NCNU, 2015). In the mission statement of National Taipei University (NTPU), which is located in Taipei City, the president wants to transform the passiveness of dealing with internationalization into proactive attraction (NTPU, 2015). Meiho University, a technological university in Southern Taiwan, states internationalization as one of its philosophies of education (Meiho University, 2015).

Though the importance of internationalization of higher education is generally recognized, how attractive internationalization of higher education is to senior high school students has not been formally researched so far. The purpose of the present study is going to conduct a formal research on this field to find empirical evidence of this issue.

\section{Methodology}

According the purpose of the present study, the researcher has to collect data from senior high school students to explore how they perceive internationalization of higher education. Qualitative design is applied in this research to find out the patterns and scopes of students' description of their perception of internationalization of higher education.

\section{Interview Questions}

As is shown in the literature review, internationalization is a complex concept and defined differently by different researchers. To adjust to the characteristics and experiences of senior high school students in Taiwan, the researcher defines internationalization as activities held by colleges or universities to increase the interaction between domestic students and foreign students and faculty. These activities include academic exchange, courses taught in English, English language training, recruiting international students, recruiting international faculty, exchange of teachers, exchange of students, and building up mutually recognized courses with foreign universities. The nine interview questions of this research are as follows:

1. What do you think of international academic exchange of a university? Why?

2. What do you think of university courses taught in English? Why?

3. What do you think of English training for all students in a university? Why?

4. What do you think of recruitment of international students by a university? Why?

5. What do you think of recruitment of international faculty by a university? Why? 
6. What do you think of exchange of faculty between domestic and foreign universities? Why?

7. What do you think of exchange of student between domestic and foreign universities? Why?

8. What do you think of building up of mutually recognized courses between domestic and foreign universities?

9. Do you think the level of internationalization will affect your choice of a university? Why?

\section{Participants}

Participants of the present study were recruited from a senior high school in central Taiwan. Senior high school students in Taiwan are streamed into two groups (liberal art group and science group) according to their aptitudes and interests since the second year. To increase the diversity of the participants, the researcher recruited male and female senior students from different classes of both liberal art group and science group. Eight participants in total were recruited and referred to as Liberal Art Male 1 (LM1), Liberal Art Male 2 (LM2), Liberal Art Female 1 (LF1), Liberal Art Female 2 (LF2), Science Male 1 (SM1), Science Male 2 (SM2), Science Female 1 (SF1), and Science Female 2 (SF2).

\section{Procedures}

Before the interview of each participant, an appointment was made according to the principle that the participants were not affected by an important coming event so that the participants can concentrate on the interview. A quiet and safe place without the interruption of other people was arranged. The researcher told each participant that the interview would be recorded, but the content would be kept confidential and only be used in the research report without revealing his/her true name. The participants could answer the interview questions with ease.

All the interviews were conducted in Chinese during April of 2015 and were finished within two weeks. Transcriptions were made after the all interviews and data were analyzed to yield the results in the next section. Quoted transcriptions are translated into English by the researcher who is an English teacher.

\section{Results}

Results show that there are a number of positive aspects of internationalization of higher education perceived by senior high school students. However, the positive view do not appear without concern. The results of the interview will be presented and discussed in three parts: (a) positive aspects of internationalization of higher education perceived by senior high school students; (b) concerns of internationalization of higher education perceived by senior high school students; and (c) internationalization as an attraction to senior high school students. The first two parts correspond to the first eight interview questions and the third part correspond to the last interview question. The results of the last interview question is discussed separately because it corresponds to main purpose of this study.

\section{Positive Aspects of Internationalization of Higher Education Perceived by Senior High School Students}

On each of the questions about internationalization of higher education, students mostly have positive perceptions. Detailed results are presented and discussed according to the subjects of interview questions below.

Academic exchange. There are four positive aspects about academic exchange-international perspective, knowledge, social, and economy. These four aspects are discussed below.

The international perspective aspect of academic exchange and its related notions like broadening horizons and worldview appear to be dominant in the participants' answers. Each participant that mentions international 
perspective believes that academic exchange is advantageous in enhancing it:

I think it is not bad. Because students can enhance their international perspective without going out of Taiwan. (LM2-Q1)

I think it is very good. It can broaden students' horizons. (LF1-Q1)

I think it is great. It can broaden our worldview. (LF2-Q1)

It will bring us international perspective and knowledge about the learning condition and needs in other counties. (SF1-Q1)

The knowledge aspect of academic exchange involves both specialized and general knowledge. Knowledge from different countries is formed in different social, political, economic, and cultural context and is liable to differ in some ways. By international academic exchange, students are exposed to a more diversified knowledge system which is helpful to broaden or deepen the scope of students' knowledge:

I think it is not bad. Because there can be different knowledge. Because the knowledge here and abroad must be different. (SM1-Q1)

The social aspect of academic exchange involves the social interaction between domestic and foreign students and faculty. Friendship is likely to build up during the process, which could lead to more interactions in the future. These interactions maybe be either formal academic activities or private communications, both of which are beneficial to the future development of students' academic and personal life:

I think it is necessary. It is highly expected. I strongly expect to make foreign friends. I think we cannot just stay in Taiwan. I want to go out and walk around. Then, I must need some friends outside. The countries I want to visit will mostly be the ones where my friends live. (LM1-Q1)

The economy aspect of academic exchange associates with saving money from the activities which might cost more if held abroad. The quote from LM2-Q1 above implies that students do not exclude strengthening international perspective by resources domestically available, and the student assumes that academic exchange provide such resources.

Courses taught in English. There are two facets in the purpose of courses taught in English. The first facet is about knowledge acquisition. Courses taught in English are supposed to strengthen students' ability to acquire knowledge in English in both audio and written forms. That is, they should be able to understand what people talk about when they listen to a lecture, presentation, or even an informal talk. They should also be able to read and understand literature of a certain topic in English. The second facet is about knowledge sharing. Students are expected to share knowledge in English with international people by speaking or writing. That is, they should be able to talk about a certain topic in English in formal or informal situation, like a conference presentation or a casual discussion with international people.

Results from the present research indicate that the students mostly agree with the practice. There are two positive views on this practice: a good practice and a necessary practice.

Courses taught in English as a good practice means it has apparent benefits for students- to increase students' English opportunities to use English and thus build up students' English competency. This view is based on the recognition that English is the most commonly used language in the world and its importance is unquestionable:

Although it might be difficult for high school students from remote areas, but I think it is good, because English is important later on in our career. It might be hard, but it is good if students can catch up. (LM2-Q2) 
I think it is also good because English is the language we use in international communication after all. English is also important to us now. (LF1-Q2)

Courses taught in English as a necessary practice is advocated by students who see the necessity of English competency in international communication:

It is necessary. Nowadays, the international perspective is widely advocated and English is a necessary second language to connect with the international community. English courses will promote students' English proficiency. (SF1-Q2)

English training. Colleges and universities providing English training are agreed upon with three positive aspects: (a) good for study; (b) good for future jobs; and (c) good for home economy. It is good for study because many university textbooks are in English. English training is helpful to boost students' understanding of these textbooks and thus good for study itself. Besides, students will need English skills if they take a master's program. English training is good for students' future jobs, because there are chances when students meet people from around the world in their jobs. English training is good for students' home economy, because their parents may not be able to provide extra recourses for them to study English. English training at universities may help them save money and study English at the same time:

I think it is helpful, because textbooks in colleges are all in English. And it will help familiarize ourselves with English. After graduation, students will have opportunities to meet people from around the world no matter he takes a master's program or a job. In that situation, English proficiency is very important. (SM1-Q3).

It is good. Some students do not do well in English, because their families are not well-off enough to support their learning, like hiring a tutor. They memorize many new words, but their listening and speaking are week. So, they still need training in college. (SM2-Q3)

Recruiting international students. Recruiting international students is a more controversial practice. Both positive sides and concerns exist. In the present study, it is perceived positively in three aspects-social, knowledge, and language.

Participant LM1 gives similar answers to academic exchange and recruiting international students. The social aspect of recruiting international students concerns interaction between domestic students and international students. These interactions build up friendship, social and intercultural skills, and attitudes, providing basis for walking out:

I think it is very good. I want to make friends with students from other countries. (LM1-Q1)

To be honest, Taiwan is truly a little too small. I really think we need to walk out as long as we can. (LM1-Q4)

The knowledge aspect of recruiting international students refers to the knowledge that domestic students acquire from formal and informal interactions with international students. International students are raised in different cultures and can bring knowledge based on their own experiences in their own cultures. This can broaden and hopefully deepen knowledge of domestic students:

It is good because we can access their lifestyle. They can tell us what happened in their own countries. They can tell us what people do in other countries outside of Taiwan. We can take this chance to understand cultures in other countries. (SF2-Q4)

The language aspect of recruiting international students is about how domestic students can train their language proficiency, usually English, through formal and informal interactions: 
It is not bad. We can strengthen our English proficiency through everyday conversation or after class discussion. (SF1-Q4)

Recruiting international faculty. Recruiting international faculty is also perceived positively by most participants.

Two positive aspects emerge from participants' answers - knowledge and language, which is similar to recruiting international students.

The knowledge aspect of recruiting international faculty refers to the knowledge that students can get from foreign teachers, which is different from the knowledge that they get from domestic teachers due to the differences of cultural background of the teachers:

I think it is also ok. Foreign teachers do not necessarily teach poorly. But I think they will bring different cultures and combined with our own. They will also bring their knowledge and special customs. (LM1-Q5)

I think it is ok. Domestic teachers may be restricted by Chinese cultural background. Listening to teachers from different countries may get different points of view and we may learn more. (LM2-Q5)

We can also learn professional knowledge directly from English sources. There will be certain gap if we learn by translation. (SM1-Q5)

The language aspect of recruiting international faculty means that students can be exposed to foreign language context, and thus try to apply their language skills in real life situation, which is helpful in language learning. Foreign language often refers to English:

I feel it is good. We can learn daily expressions of English which we cannot learn from our own people. (SM1-Q5)

It is ok. Because foreign teachers may teach in English. You may try to strengthen your English competency to understand what they teach. They may also talk to you in English about something outside our country. We can know about the world outside Taiwan through them. (SF2-Q5)

Exchange of faculty. For students, exchange of faculty is very similar to recruiting international faculty in that students are taught by foreign teachers in both cases. The difference lies in the status of teachers. Recruited international faculty members belong to the colleges or universities which recruit them while exchanged faculty members just go to the partner colleges or universities temporarily, usually a semester or a year depending on the content of the exchange programs. Two positive aspects can been found from the exchange of faculty-knowledge and economy.

The knowledge aspect of exchange of faculty comprises two parts - teacher and student. For teachers, the faculty members who join exchange programs expand their own knowledge scope and depth since they are exposed to a different culture, living in a different country and teaching different students. These experiences can broaden domestic teachers' horizons in the end and come back to benefit students at home countries.

For students, they are taught by teachers coming from different cultures and have different learning experiences in class. Like recruited international faculty members, exchanged faculty members bring the knowledge and culture to the classes they teach here and can expand students' horizons:

It is ok. Teachers who go abroad can broaden their horizons, and then come back to benefit their students. (LM2-Q6)

It is very good. It is good for the teachers, because they can teach in different contexts and learn new things. Students can also learn from teachers from different countries and broaden their horizons. It is good for both teachers and students. (SF1-Q6)

It is ok. We can learn from the foreign teachers' perspective. From these foreign teachers, we may acquire new knowledge domestic teachers may not know. (SF2-Q6) 
The economy aspect of exchange of faculty refers to saving money for students who can experience foreign teachers' teaching without going abroad, especially those students whose families are not well-off and cannot go abroad to study for a master's or doctoral degree:

It is ok. In fact, I expect so a lot. Some students' families are not so well-off and cannot go abroad for a master's or doctoral degree. If we can exchange teachers, we will be able to experience how they teach. (LM1-Q6)

Exchange of students. Exchange of students seems to be the most favored practice of internationalization of higher education. All participants agreed with this practice with different levels of passion. Exchanged students have similar study experiences to those of the students who go abroad to study for a degree. However, the cost is generally lower than studying abroad for a degree. Exchanged students often take a few courses in the partner colleges or universities which can be counted in the program requirements at home colleges or universities. The status of exchanged students are often called "visiting students". The partner colleges or universities will not award degrees to visiting students since they usually stay only a short period of time, usually no more than one academic year, and cannot fulfill the requirements to be awarded degrees. However, visiting students do have the experiences of studying abroad. Four positive aspects are found in the responses of the participants - experience, knowledge, language, and economy.

The experience aspect of exchange of students is about the experiences of living abroad. It is not the same as traveling abroad and staying in hotels. The experiences are a composite of studying and living in a different culture:

It should benefit students from both sides greatly. Students can contact an unfamiliar country and its culture and try to assimilate into it. If my language proficiency is good, I will try to win the opportunity to be visiting students. (LF2-Q7)

It is ok. I think those who want to be visiting students mostly want to experience life in different cultures. (SM2-Q7)

The knowledge aspect of exchange of students refers to the benefit of studying at a partner college or university and acquire knowledge there. The knowledge may not be acquired at home colleges or universities:

It can broaden students' horizons, access different environments, and acquire different knowledge. (SF1-Q7)

It is good. I always want to walk out of Taiwan. It is not a good thing to stay in the place which we are used to all the time. I can know their cultures and learn some knowledge that we may not be able to learn in our own country. (SF2-Q7)

The language aspect of exchange of students refers to the opportunities for visiting to learn a foreign language by living in an environment where the language is intensively used. Visiting students are required to use the official language in the partner colleges or universities. This will definitely provide a good opportunity for them to develop language skills in a more natural and intensive manner:

I also like to improve my language proficiency and also learn some knowledge in other countries which may be good for use in Taiwan. (SM2-Q7)

The economy aspect of exchange of students, like answers of other questions in the interview, refers to the fact that students can get some benefits from the practices of internationalization of higher education without spending a lot of money. Oftentimes, visiting students will only pay the tuition fee required by domestic colleges or universities. This is usually money-saving for them:

It is good, especially for some students whose families cannot support them to study abroad. It helps them acquire similar experiences. (LM2-Q7) 
Mutually recognized courses. Mutually recognized courses are a kind of practice to encourage students to find more resources from colleges or universities abroad. In fact, this practice is designed for students who join exchange programs. Two positive aspects of this practice emerge - saving time and unique learning experiences.

Students might be concerned about the possible delay of their graduation if they spend an extra year or semester abroad. If the courses taken abroad are counted in the program requirements at home colleges or universities, students will not have to worry about delayed graduation problem. Saving time is the most prominent aspect of this practice:

I feel it is great. It is nice to go to another country and take credits that are valid in our won university. It can prevent us from delaying graduation or flunking out for failing more than half credits. (LM1-Q8)

Then I do not have to take extra courses. (LF2-Q8)

It is ok. It can decrease students' burden. (SM2-Q8)

Unique learning experiences are the second positive aspect of this practice. Students taking courses abroad have the privilege to study in a culturally different environment which makes them different from those who do not have similar experiences:

It is very good. It will make me unique, different from others. (LF2-Q8)

\section{Concerns of Internationalization of Higher Education Perceived by Senior High School Students}

Results from the present research indicate that students mostly agree with the practices of internationalization of higher education. However, concerns also exist in part of these practices, including courses taught in English, English training, recruiting international students, recruiting international faculty, exchange of faculty, exchange of students, and mutually recognized courses. These concerns are presented in the following section item by item.

Courses taught in English. Since students have different levels of English competency and there are different views on professional knowledge and language proficiency, courses taught in English can be a dependent practice, which means that it should be done only under certain conditions. Below are the conditions proposed by the participants:

1. Students' English competency is above the necessary level;

2. The level of difficulty of the course content is easy enough for students to understand;

3. Students are willing to work hard to conquer the difficulty of courses taught in English.

At least one of the above conditions should be met:

As for courses taught in English, I think it depends on the English competency of that university. Students of some universities are not so good at English. It is also dependent on the level of difficulty of the content the teacher teaches. If the course content is difficult and students are not diligent, it not necessary. It is ok if students are willing to work hard. (LM1-Q2)

If students' English is mostly bad, it is not practical. (LF2-Q2)

English training. English training for all students seems to be a normal idea in the era of globalization. There are still concerns that it might not fit all fields of study. In other words, not all departments of a college or university need high levels of English competency:

I think it depends on field of discipline. Some departments will not necessarily use English. So, I think it should depend of the field of study. (LF1-Q3) 
Recruiting international students. Concerns about recruiting international students have to do with the admission opportunities which domestic students struggle for. Domestic students might not like the ideas that international students take up too many admission opportunities and influence domestic students' rights:

It can increase interactions with foreigners. But some may not like the idea, because it may decrease the admission opportunities of domestic students. I think it is ok to recruit international students, but only a small number of them. (LM2-Q4)

It is ok as long as it does not threaten domestic students' rights. (SM1-Q4)

Recruiting international faculty. Recruiting international faculty is accepted or even favored by most participants.

Despite the mostly positive opinions proposed by the participants, there are still concerns in two aspects - affinity and knowledge learning.

The affinity aspect of the concern refers to teachers from different countries might have apparent distance from domestic students because their cultures are very different from ours. Students might not feel comfortable talking with these foreign teachers, especially when they have questions to ask:

I probably will be afraid because foreigners give me a sense of distance. I will probably keep foreign teachers in a distance and do not feel comfortable to ask them questions. (LF2-Q5)

The knowledge learning aspect of the concern has to do with language competency. Oftentimes, students acquire knowledge more easily by the language that they are most familiar with. When they try to acquire knowledge through a foreign language, they might miss some points because of the language barrier. Even though they have been good at a foreign language, say English, they still have a kind of unnatural feeling compared with using the first language:

It might be good for language learning, but it is unclear for specialized knowledge acquisition. (SM2-Q5)

Exchange of students. Exchange of students is favored by most participants, but there is still concern from students' parents. If parents do not agree on the students' plans to go abroad, they cannot join the exchange programs:

I would love to go abroad a lot, but my parents will not agree. (LF2-Q7)

Mutually recognized courses. Mutually recognized courses are also a practice that receives positive opinions from most participants. Perhaps it is because this practice has no direct negative effects on students but provides more options to choose from. Judging from the school administrative point of view, however, it makes the school administration more complex and takes more time to provide such services. It might not be necessary to provide such services for each field of study:

It depends on the nature of a department. It is not necessary for every department to do that. Only the highly specialized field like medicine needs to do so, because it can use the resources abroad to complement the needs of domestic university. Generally speaking, we can go to graduate institute for advanced study. It is not necessary to get too complicated. (LM2-Q8)

\section{Influence of Internationalization of Higher Education on Students' Choices of Universities}

The results of the present study indicate that practices of internationalization of higher education are mostly accepted or favored by the participants. But there are still concerns that might influence students' 
evaluation of these practices. The last interview question is about how these practices influence students' choices of universities and should be discussed separately, because it is about the overall evaluation of these practices and should put favors and concerns into consideration altogether.

As expected, most participants agree that internationalization of higher education will influence students' choices of universities. The higher the level of internationalization, the more attractive a university will be:

Higher level of internationalization will help us walk out faster and not to be confined to Taiwan. It is definitely helpful. (LM1-Q9)

Yes, it will influence my choice of which university to go to.

Yes, these practices of internationalization are attractive to me. All of these practices are all necessary, because the basics are important. (SM1-Q9)

One participant does not consider internationalization as the most important factor in her choice of university, but she still likes the one with higher level of internationalization when other conditions are the same:

No, it is not the most important condition under consideration. But if two universities have the same conditions except the level of internationalization, I will choose the one with higher level of internationalization. (SF2-Q9)

\section{Discussion}

The results of the present study show that internationalization of higher education is mostly perceived as positive by the senior high school student participants. There are a few concerns in some of the practices. The pros and cons are discussed below.

According to Qiang (2003), there are various reasons for arguing the importance of internationalization of higher education. First, the academic and professional requirements for graduates increasingly reflect the demands of globalization, and higher education institutes have to prepare students to meet the requirements, including academic and professional knowledge, multilingualism, social and intercultural skills, and attitudes. Second, the level of specialization in research and the size of investments indispensable to certain fields of research and development need collaborative efforts and intensive international cooperation. Third, the recruitment of international students has become an important source of institutional income and national economic interest. Fourth, the use of new information and communication technologies (ICT) in the delivery of education helps facilitate the internationalization of higher education. These four reasons match with the eight practices of the present study closely as shown in Table 1.

Table 1

Four Reasons and Eight Practices of Internationalization of Higher Education

\begin{tabular}{|l|l|}
\hline The four reasons & Eight practices \\
\hline $\begin{array}{l}\text { Academic and professional requirements_academic and } \\
\text { professional knowledge, multilingualism, social and } \\
\text { intercultural skills, and attitudes }\end{array}$ & $\begin{array}{l}\text { Academic exchange; } \\
\text { Courses taught in English; } \\
\text { English training; } \\
\text { Recruiting international students; } \\
\text { Recruiting international faculty; } \\
\text { Exchange of faculty; } \\
\text { Exchange of students. }\end{array}$ \\
\hline Collaborative efforts and intensive international cooperation & Academic exchange \\
\hline Recruitment of international students as economic interest & Recruitment of international students \\
\hline Use of ICT in delivery of education & Mutually recognized courses \\
\hline
\end{tabular}


As Table 1 shows, students' academic and professional knowledge, multilingualism, social and intercultural skills, and attitudes can be developed through academic exchange, courses taught in English, English training, recruiting international students, recruiting international faculty, exchange of faculty, and exchange of students. Some of the practices have multiple functions and can meet more than one purpose. For instance, recruiting international students can develop students' multilingualism, social and intercultural skills, and attitudes. It also brings economic interest to the higher education institution and the nation as a whole.

In addition to developing students' academic and professional knowledge, academic exchange can also involve international cooperation. It can also develop students' language and social and intercultural skills during the encounter of the two sides engaging in the exchange.

Judging from the overall responses of the participants, students mostly recognize the importance of internationalization of higher education. The concerns proposed by participants seem to be minor ones. Language proficiency might be a problem, but enhancing students' language proficiency is one of the major objectives of internationalization. English might not be used for all courses, but it is useful for all students in their lives. The number of international students recruited can be set in a proper scale. Foreign teachers are not always hard to get along with. On the contrary, some may be very kind and nice. Oppositions from parents against going abroad are not necessarily common among all parents and can be solved by adequate communication. Mutually recognized courses are practical as long as there are enough personnel to take charge of them.

A repeated theme emerges from the study - walking out. All the eight practices of internationalization are more or less related to the theme. Academic exchange involves visiting each other for academic activities, which is a kind of walking out. Courses taught in English and English training prepare students to communicate knowledge internationally, which is a kind of preparation for walking out. Recruiting international students build up international friendship and intercultural and social skills and may also be a kind of preparation to walk out. Recruiting international faculty and exchanging with international partners bring international perspective, knowledge, and skills and can also be considered preparations for walking out. Exchange of students is the real action to walk out and mutually recognized courses are a supporting measure to help students walk out. The motivation to walk out is expanding the world beyond Taiwan, which is just a small island. However, the lack of foreign language competency is a major concern when communication in foreign language is needed. Parents' support is also indispensable. When opposition from parents occurs, walking out is very likely to be hindered. Besides, recruiting international students might influence domestic students' admission opportunities and the number should be limited. The necessity of some practices is also to be considered fully.

\section{Conclusion}

The purpose of the present study is to investigate how senior high school students perceive internationalization of higher education. Results show that internationalization of higher education is perceived positively by most participants and will mostly influence students' choices of universities. "Walking out" is the main theme of students' responses and lack of foreign language competency is a major concern. Lack of parents' support will likely hinder the actions to walk out. Recruiting international students is also accompanied by a concern that it might influence domestic students' admission opportunities. Necessity of some practices is a problem proposed by the participants. 
In brief, most participants recognize the importance of internationalization and are willing to walk out to see different world outside of Taiwan. However, some possible problems must be addressed. According to the results of the present study, some recommendations are proposed for students, higher education sectors, and future researchers.

Students are encouraged to enhance their foreign language proficiency to cross the barriers of communication. If there is opposition from parents against their plans to walk out, they need to communicate with them about the concerns that can be addressed appropriately and tell them the benefits of their plans. They are also encouraged to have more interactions with international teachers and students to cultivate their social and intercultural skills and attitudes. They are also encouraged to join the exchange programs to really walk out and see the world outside Taiwan.

Higher education sectors must support students' needs to go international and build up a comprehensive administrative system to work on the details of every practice of internationalization of higher education. Possible concerns that might arise from the practices must be addressed appropriately, like recruiting international students which might influence the admission opportunities of domestic students. It is necessary to clarify the policy of recruiting international students and how it benefits domestic students by providing an international environment at the university campus.

Future researchers who are interested in further exploration of this topic need to collect quantitative data from a larger student population to get more generalizable conclusions. It is also necessary to include more content in the interview questions, like internationalized courses, to explore more facets of internationalization of higher education.

\section{References}

Anderseck, K. (2004). Institutional provision of higher education: Do universities need GATS? Higher Education Management and Policy, 14(3), 77-92.

Ardakani, F. B., Yarmohammadian, M. H., Abari, A. A. F., \& Fathi, K. (2011). Internationalization of higher education systems. Procedia-Social and Behavioral Sciences, 15, 1690-1695. doi:http://dx.doi.org/10.1016/j.sbspro.2011.03.353

Bordean, O. N., \& Borza, A. (2013). Internationalization of higher education institutions: The case of Romania. Procedia-Social and Behavioral Sciences, 92, 98-103. doi:http://dx.doi.org/10.1016/j.sbspro.2013.08.643

Deem, R., Mok, K. H., \& Lucas, L. (2008). Transforming higher education in whose image? Exploring the concept of "world-class" university in Europe and Asia. Higher Education Policy, 21, 83-97.

Dictionary.com (2015). Perceive. Retrieved from http://dictionary.reference.com/browse/perceive?s=t

Ellingboe, B. J. (1998). Divisional strategies to internationalize a campus portrait: Results, resistance, and recommendations from a case study at a U.S. university. In J. A. Mestenhauser, \& B. J. Elllingboe (Eds.), Reforming the higher education curriculum: Internationalizing the campus (pp. 198-228). Phoenix, A.Z.: American Council on Education and Oryx Press.

Feng, J. H. (2015, January 19). Incentives of Hong Kong Universities - Close to Taiwan, high level of internationalization, and cheaper fee than European and American universities. United Daily News. Retrieved from http://udn.com/news/story/6928/651239-\%E6\%B8\%AF\%E6\%A0\%A1\%E8\%AA\%98\%E5\%9B\%A0\%EF\%BC\%9A\%E9\%9 В\%A2\%Е5\%8F\%B0\%Е8\%BF\%91\%Е3\%80\%81\%Е5\%9C\%8B\%Е9\%9A\%9B\%Е5\%8C\%96\%Е3\%80\%81\%Е8\%BC\%83\% E6\%AD $\% 90 \% \mathrm{E} 7 \% \mathrm{BE} \% 8 \mathrm{E} \% \mathrm{E} 4 \% \mathrm{BE} \% \mathrm{BF} \% \mathrm{E} 5 \% \mathrm{AE} \% 9 \mathrm{C}$

Hamrick, J. (1999). Internationalizing higher educational institutions: Broadening the approach to institutional change (Paper presented to the Managing Institutional Change and Transformation Project, University of Michigan). Retrieved from http://www-personal.umich.edu/ marvp/facultynetwork/whitepapers/jimhamrick.html

Knight, J. (1993). Internationalization: management strategies and issues. International Education Magazine, 9(6), 21-22.

Maudarbekova, B., \& Kashkinbayeva, Z. (2014). Internationalization of higher education in Kazakhstan. Procedia-Social and Behavioral Sciences, 116, 4092-4097.

Meiho University. (2015). Education philosophy. Retrieved from http://www.meiho.edu.tw/files/11-1000-123-1.php 
Ministry of Education, Culture, Sports, Science and Technology, Japan. (2008). 2008 white paper on education, culture, sports, science and technology. Retrieved from http://www.mext.go.jp/b_menu/hakusho/html/hpab200801/1292564.htm

Ministry of Education. (2001). White paper on university education policy. Retrieved from http://english.moe.gov.tw/lp.asp?Ct Node $=11411 \&$ CtUnit $=1332 \&$ BaseDSD $=16 \& m p=1 \&$ nowPage $=2$ \&pagesize $=15$

Ministry of Education. (2015). Stats of colleges and universities for academic year 2014. Retrieved from https://stats.moe.gov. tw/bookcase/Higher/103/index.html \#p=26

National Chi Nan University (NCNU). (2015). About National Chi Nan University. Retrieved from http://www.ncnu.edu.tw/ ncnuweb/

National Taipei University (NTPU). (2015). Presidents ' philosophy and vision. Retrieved from https://www.ntpu.edu.tw/about/ about4.php

Qiang, Z. (2003). Internationalization of higher education: Towards a conceptual framework. Policy Futures in Education, 1(2), 248-270.

Yang, C. L. (2004). The meaning and debate of internationalization of higher education. Education Policy Forum, 7(1), 101-110. 